\title{
Oral Impairment During Swallowing
}

National Cancer Institute

\section{Source}

National Cancer Institute. Oral Impairment During Swallowing. NCI Thesaurus. Code C127179.

An assessment of an individual's oral impairment during swallowing. 